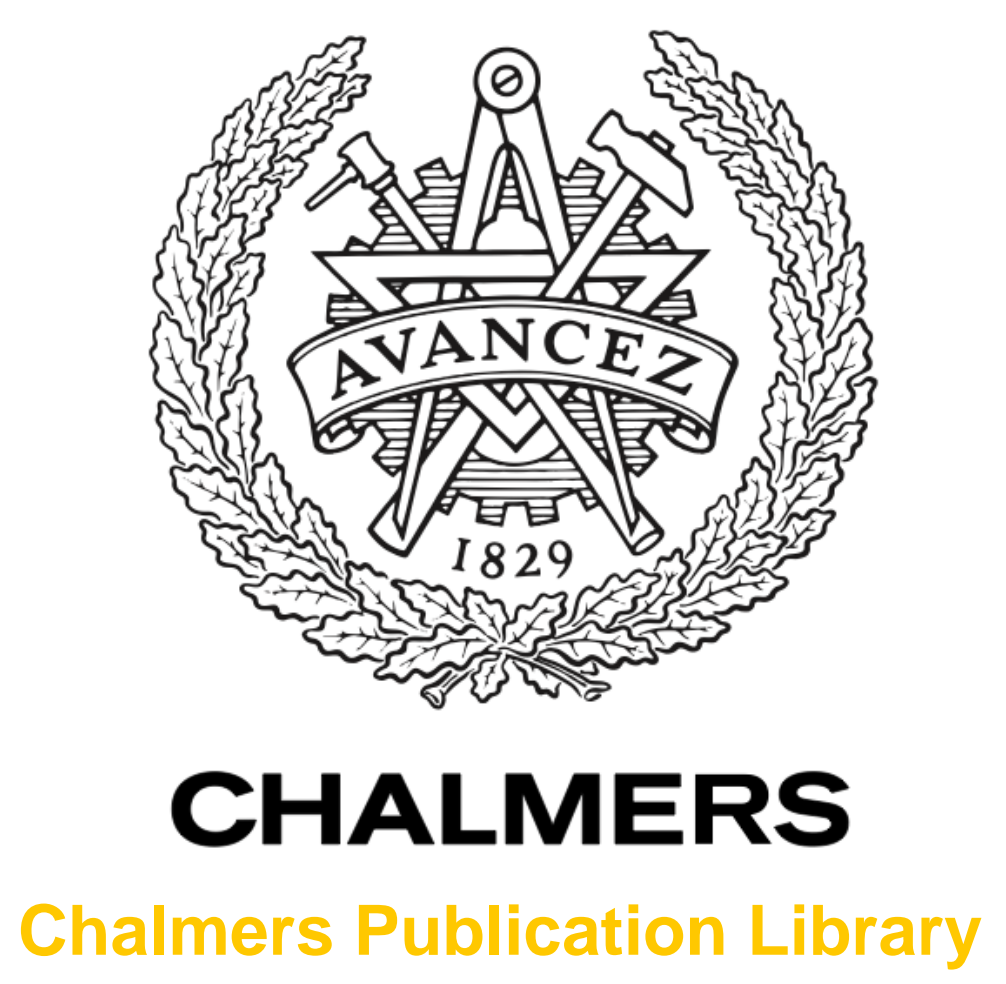

\title{
Assessment of the energy and economic performance of second generation biofuel production processes using energy market scenarios
}

This document has been downloaded from Chalmers Publication Library (CPL). It is the author's version of a work that was accepted for publication in:

Applied Energy (ISSN: 0306-2619)

Citation for the published paper:

Heyne, S. ; Harvey, S. (2013) "Assessment of the energy and economic performance of second generation biofuel production processes using energy market scenarios". Applied

Energy, vol. 101 pp. 203-212.

http://dx.doi.org/10.1016/j.apenergy.2012.03.034

Downloaded from: http://publications.lib.chalmers.se/publication/164519

Notice: Changes introduced as a result of publishing processes such as copy-editing and formatting may not be reflected in this document. For a definitive version of this work, please refer to the published source. Please note that access to the published version might require a subscription.

Chalmers Publication Library (CPL) offers the possibility of retrieving research publications produced at Chalmers University of Technology. It covers all types of publications: articles, dissertations, licentiate theses, masters theses, conference papers, reports etc. Since 2006 it is the official tool for Chalmers official publication statistics. To ensure that Chalmers research results are disseminated as widely as possible, an Open Access Policy has been adopted.

The CPL service is administrated and maintained by Chalmers Library. 


\title{
Assessment of the energy and economic performance of second generation biofuel production processes using energy market scenarios
}

\author{
Stefan Heyne*, Simon Harvey \\ Division of Heat and Power Technology - Department of Energy and Environment \\ Chalmers University of Technology, Gothenburg, Sweden \\ e-mail: stefan.heyne@chalmers.se, simon.harvey@chalmers.se
}

\begin{abstract}
In this paper performance assessment of second generation biofuel production using energy market scenarios and system-level performance indicators is proposed. During biofuel production a number of products and services can be co-generated while import of energy services (e.g. electricity and heat) in addition to the fuel supply may also be needed. This needs to be reflected by a well-defined performance indicator enabling a comparison between different process alternatives. A marginal production perspective is proposed in this study for the definition of a general energy performance indicator, recalculating all services to primary energy on a system level. The Energy Price and Carbon Balance Scenarios (ENPAC) tool developed at Chalmers is used for the definition of the energy system background. Thereby, a scenario-specific comparison of the processes' thermodynamic, economic and carbon footprint performance is possible. The usefulness of the approach is illustrated for production of synthetic natural gas (SNG) from biomass. The shortcomings of common performance indicators are also discussed.
\end{abstract}

Keywords: energy systems; biorefinery; performance indicators; biofuels; energy market scenarios; synthetic natural gas

\section{Introduction}

Significant increase of production of biofuels for transportation has sparked much debate among researchers and policy-makers. On the one hand, biofuels are seen as a powerful option for greenhouse gas (GHG) emission reduction, for reducing fossil fuel dependency, as well as for local job creation in rural areas [1] and their use is promoted by targets for a $20 \%$ renewable energy share within the transport sector by 2020 in the European Union [2]. In particular the concept of biorefineries - resulting in a spectrum of products using an integrated upgrading system - has become a promising concept for efficient production of biofuels [3]. On the other hand their impact on food production and prices as well as their climate change mitigation potential is uncertain, as evidenced by a number of studies that present contrasting results (see for example [4, 5]). A general consensus is that there is a need for identification of sustainability criteria for biofuel production in order to be able to compare different alternatives on a common basis and to assess their actual potential regarding different aspects $[6,7]$.

${ }^{*}$ Corresponding author 
Cherubini et al. [8] illustrate an approach based on life cycle analysis (LCA) with a case study of a biorefinery concept based on crop residues. They show large potential for GHG emission reduction and non-renewable energy saving, but also an increased eutrophication potential compared to a fossil reference system. In addition, sensitivity of the results - in particular for the GHG emission reduction potential - to land use change effects are highlighted by Cherubini et al. [8] Another prominent example of a major comparative study that also adopts an LCA perspective within the biomass-based transportation fuel sector is the JRC-EUCARCONCAWE well-to-wheel study [9], in which second generation biofuels are recognized to have a high GHG emission reduction potential. The latter study has been analysed by Wetterlund et al. [10] who note that it has a major shortcoming by not taking into account the fact that biomass is not an unlimited resource. Increased use of biomass within the transport sector most likely will cause a deficit of biomass within another energy sector in the future. Covering this deficit with a fossil alternative will cause an increase of $\mathrm{CO}_{2}$ emissions on the overall system level, thereby drastically reducing the GHG emission reduction potential of several biofuel options within the transportation sector. The concept of system expansion is adopted in reference [10] which accounts for alternative use of biomass within an assumed energy system background. Differing assumptions for the background system are also shown to have a major effect on the results of the cost-effectiveness of $\mathrm{CO}_{2}$ abatement costs for different bioenergy technologies in an Austrian context [11]. Further, Daianova et al. [12] investigate bioethanol and biogas production as transport fuels within a regional context taking into account local conditions. The latter analysis is however restricted to cost optimization and does not investigate $\mathrm{CO}_{2}$ consequences and system efficiencies.

Other approaches for taking into account the surrounding system within LCA-based studies include the introduction of exergy based indicators (e.g. [13]) or the use of system perturbation (e.g. [14]). The latter approach allows adapting LCA to regional conditions.

In this study the ENPAC tool [15] developed at Chalmers within the EU Pathways project [16] is used for the necessary energy system background definition. The tool can be used to generate consistent scenarios depicting possible cornerstones of future energy markets. Based on these scenarios a systematic evaluation of biofuel production processes is possible as the background energy system is specified with corresponding reference technologies for the different energy services, including appropriate conversion efficiency values for these technologies. Energy and economic efficiency, as well as $\mathrm{CO}_{2}$ emission consequences, of the introduction of second generation biofuel processes can be analysed as illustrated in this paper for production of synthetic natural gas (SNG) from biomass feedstock. The capability of the energy market scenario tool is thereby extended to allow a multifaceted scenario-specific evaluation of different processes, enabling identification of robust alternatives not only from an economic, but also from a thermodynamic and environmental viewpoint.

\section{Methodology}

In order to be able to evaluate the performance of a new process that is to be introduced to an existing background energy system, it is important to clearly define the system boundaries 
and the underlying assumptions for the evaluation. The life-cycle-perspective for this study is a well-to-tank perspective meaning that no specific application for the produced biofuel is considered. This is different to other studies investigating biofuel process alternatives $[9,10]$, but the idea with this study is to not limit the application to biofuels for the transport sector but rather to adopt a general view on system energy efficiency based on the underlying scenarios. The case of SNG production that is used for illustration of the methodology in this paper might be such an example as SNG is not limited to transport applications but might also replace fossil natural gas in any of its other applications within the power or chemical sector.

The approach applied in this study is illustrated in Figure 1. Possible by-products from a new process such as heat and electricity compete with reference technologies within the existing energy system and thereby indirectly influence the overall performance of a new process considering energy efficiency and $\mathrm{CO}_{2}$ emission consequences. Even the feedstock used for the new process is subject to competition with a reference user since biomass is not an infinite resource. Replacing biomass with an alternative - most likely fossil - feedstock in the process defined as the reference user in the background energy system has a non-negligible impact on the $\mathrm{CO}_{2}$ balance of the new process. For defining the energy system background an energy market scenario tool (ENPAC) is used as explained in more detail in Section 2.5. The time perspective of the study (and the scenario tool) is medium to long term. The different system aspects investigated in this study - energy performance, $\mathrm{CO}_{2}$ emission consequences and economic performance - are discussed in more detail in the following paragraphs.

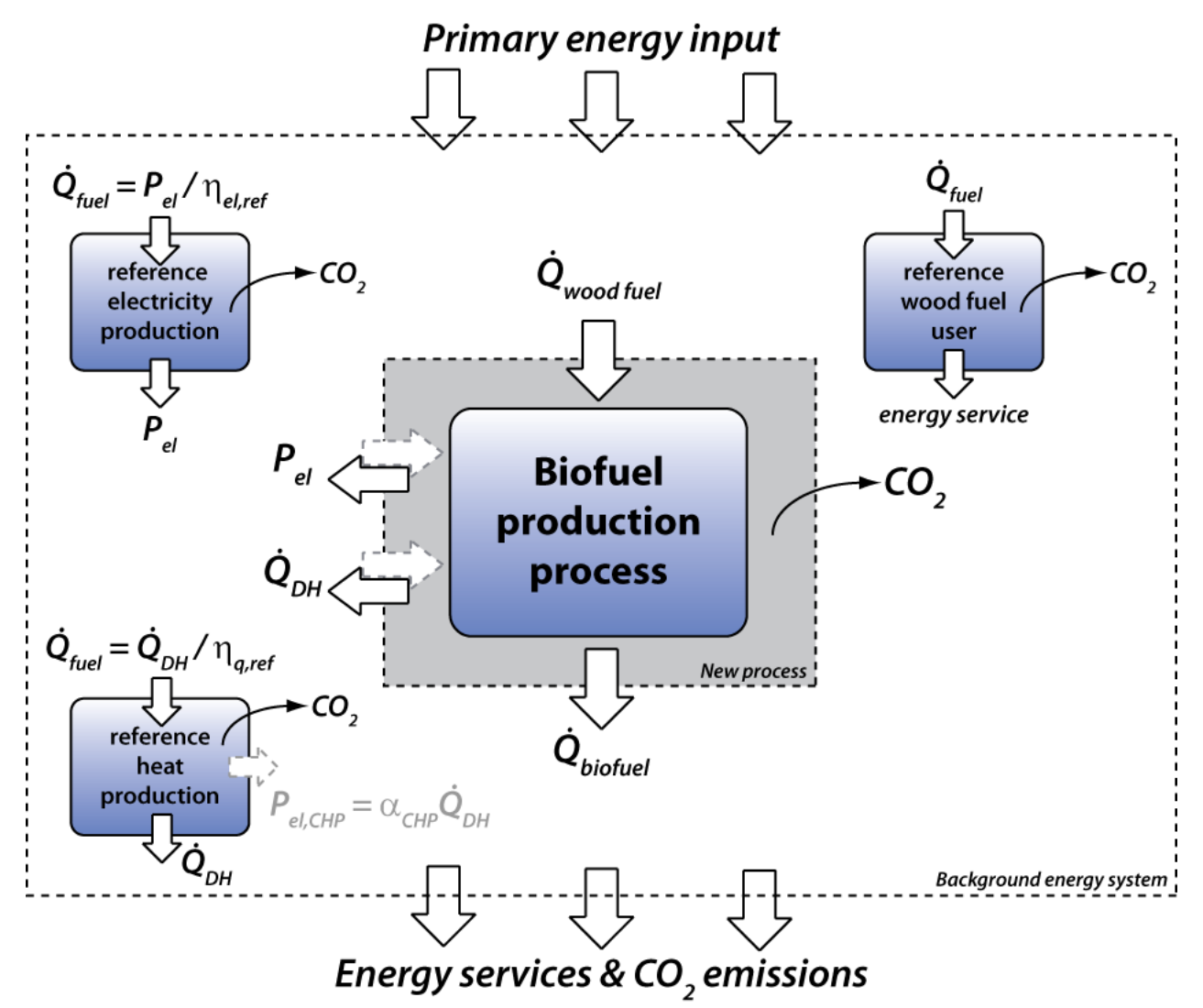

Figure 1: Schematic representation of the methodology accounting for reference services of the background energy system the new process is to be integrated into. 
The published version of the article is available at http://dx.doi.org/10.1016/j.apenergy.2012.03.034. Published in Applied Energy 2013, 101, p. 203-212, DOI: 10.1016/j.apenergy.2012.03.034

\subsection{Energy efficiency calculation}

The energy efficiency evaluation of a process can be done in various ways. The most commonly used performance indicators are the overall energy $\left(\eta_{t h}\right)$ and exergy efficiency $\left(\eta_{e x}\right)$. The definition of these two performance indicators may vary depending on system boundary definitions and conventions, but follows the general form of eqs. (1) and (2):

$$
\begin{array}{r}
\eta_{t h}=\frac{\sum_{i} \dot{Q}_{\text {prod, } i}+P_{e l}^{-}+\dot{Q}^{-}}{\sum_{j} \dot{Q}_{f u e l, j}+P_{e l}^{+}+\dot{Q}^{+}} \\
\eta_{e x}=\frac{\sum_{i} \dot{E}_{p r o d, i}+\dot{E}_{e l}^{-}+\dot{E}_{q}^{-}}{\sum_{j} \dot{E}_{f u e l, j}+\dot{E}_{e l}^{+}+\dot{E}_{q}^{+}}
\end{array}
$$

For eq. (1), $\dot{Q}_{\text {prod }}$ and $\dot{Q}_{\text {fuel }}$ are the energy values of the resulting product(s) and fuel input(s), respectively. $P_{e l}$ represents the electricity and $\dot{Q}$ the useful heat (often in form of e.g. district heating) that either is exported (superscript "-“) or imported (superscript "+"). The terms therefore only can appear either in the numerator (export) or the denominator (import). The same applies for the exergy value of electricity $\left(\dot{E}_{e l}\right)$ and heat $\left(\dot{E}_{q}\right)$ in eq. (2), where $\dot{E}_{\text {prod }}$ and $\dot{E}_{\text {fuel }}$ represent the exergy value of product(s) and fuel(s).

Energy efficiency rates all energy services at the same level not taking into account their quality. A process having a large amount of process excess heat at low temperature might therefore seem to perform better than a process exporting a smaller amount of electricity. The aspect of energy quality is accounted for in the exergy efficiency, comparing all energy service based on their theoretical maximum potential for conversion to mechanical work output. The definition of chemical exergy of a fuel (most often done according to [17]) however is not straightforward and may in addition overestimate the potential for mechanical work potential, as for example stated by Gassner [18].

For cases where new processes are designed for integration with existing ones in order to achieve synergy effects, a marginal efficiency analysing the performance of the new process only can be useful in order to compare the integrated process to stand-alone or other integration options. This has been done for example in several studies comparing different alternatives for biomass- and waste-based electricity generation by integrated solutions in fossil natural gas combined cycle plants [19-21]. A marginal efficiency for biomass/waste to electricity conversion $\eta_{e l, m a r g}$ can be defined for this kind of process according to:

$$
\eta_{e l, m \mathrm{arg}}=\frac{P_{e l, t o t}-\eta_{e l, s \tan d-a l o n e} \cdot \dot{Q}_{\text {fuel,fossil }}}{\dot{Q}_{\text {fuel,bio }}}
$$


The published version of the article is available at http://dx.doi.org/10.1016/j.apenergy.2012.03.034. Published in Applied Energy 2013, 101, p. 203-212, DOI: 10.1016/j.apenergy.2012.03.034

where $P_{\text {el,tot }}$ is the total electricity generation of the integrated process, $\dot{Q}_{\text {fuel,fossil }}$ the fossil fuel input that most likely is to be reduced by the integration compared to the stand-alone operation, and $\dot{Q}_{\text {fuel,bio }}$ the fuel input in form biomass/waste. The electrical efficiency $\eta_{e l, \text { stand- }}$ alone represents the electrical efficiency of a reference stand-alone plant, implying the assumption that the electricity generation efficiency of the cycle remains unaffected by the integration of the new process. The marginal electrical efficiency $\eta_{e l, \text { marg }}$ therefore represents the conversion from biomass/waste to electricity and can for example be compared to the efficiency of a stand-alone biomass-fired power plant to illustrate the more efficient use of biomass for electricity generation in an integrated process setup.

All efficiency definitions noted above allow comparison of different process alternatives with each other, however they only consider the processes isolated from the surroundings and do not take into account possible interactions with the background energy system. This allows for an easily accomplished and quick comparison of different process alternatives but does not give any guidance on how the new process performs from an energy system perspective, the latter being crucial for evaluating the processes' potential for implementation in real systems.

\subsection{System expansion}

In order to compensate for the drawback of the isolated energy efficiency evaluation it is necessary to expand the system and take the background energy system into account, as illustrated in Fig. 1. This can be done by recalculating all energy services supplied and consumed to primary energy using the corresponding reference conversion technology. The system efficiency $\eta_{\text {sys }}$ defined in eq. (4) compares all primary energy input into the process to all output.

$$
\eta_{s y s}=\frac{\sum_{i} \dot{Q}_{p r o d, i}+\frac{P_{e l}^{-}}{\eta_{e l, r e f}}+\frac{\dot{Q}^{-}}{\eta_{q, r e f}}}{\sum_{j} \dot{Q}_{f u e l, j}+\frac{P_{e l}^{+}}{\eta_{e l, r e f}}+\frac{\dot{Q}^{+}}{\eta_{q, r e f}}}
$$

Again, only net flows are considered, meaning that only heat/electricity import or export is accounted for in eq. (4). The efficiency terms for electricity and heat production $\eta_{e l, r e f}$ and $\eta_{q, \text { ref }}$ require specification of the reference production technologies. For the case where one of the reference energy service technologies is a co-generation application, the definition of eq. (4) has to be modified accordingly. Gassner [18] applied the concept of reference technologies in combination with exergy-based conversion efficiencies for the reference energy services to define a chemical conversion efficiency for biofuel production processes in a similar manner to that defined in eq. (4). The reference technologies were set to heat pumps for heating services and natural gas combined cycle power plants for electricity production. These are obviously optimum technologies from a thermodynamic viewpoint, but it is 
The published version of the article is available at http://dx.doi.org/10.1016/j.apenergy.2012.03.034. Published in Applied Energy 2013, 101, p. 203-212, DOI: 10.1016/j.apenergy.2012.03.034

questionable if they are the reference technologies a biofuel process to be implemented in the current or near future energy system is actually competing with.

In addition to the problem of defining the reference energy service providers, the alternative use of biomass is an important aspect when assessing the environmental efficiency in form of GHG emission reduction potential of a given process. Wetterlund et al. [10] compare two cases in their analysis of the European well-to-wheel study [9]: coal-power plants as reference users of biomass applying co-combustion and no alternative user of biomass which corresponds to assuming that biomass is available in unlimited amounts. These two cases are evaluated against a number of possible background energy systems with corresponding reference electricity production technologies in order to investigate the sensitivity of the results to the underlying assumptions. The probability of different combinations of reference electricity production technologies and alternative biomass users is not analyzed though. In the present study, an energy market scenario tool is used for the construction of consistent future energy market scenarios, allowing for the energy performance evaluation of new processes according to eq. (4). For the time perspective at around year 2030 adopted in this study it can be expected that the build-margin production technologies are still fossil-based [22] rendering the approach defined above viable (see also Section 2.5).

\section{$2.3 \mathrm{CO}_{2}$ consequences}

The change in system level $\mathrm{CO}_{2}$ emissions $\Delta C \mathrm{O}_{2, \text { sys }}$ is evaluated as emissions per energy unit of biofuel supplied

$$
\Delta C O_{2, s y s}=\frac{\Delta n_{b i o} \cdot c_{b i o}-\Delta n_{e l} \cdot c_{e l}-\Delta n_{q} \cdot c_{q}-n_{b i o f u e l}^{-} \cdot c_{\text {fossilfuel }}}{n_{\text {biofuel }}^{-}}
$$

with $\Delta n_{i}[\mathrm{MWh} / \mathrm{y}]$ being the change in use of biomass (bio) and production of electricity (el) and district heat $(q)$, respectively. $c_{i}[\mathrm{~kg} \mathrm{CO} / \mathrm{MWh}]$ are the specific emissions per unit of energy for each fuel/service $i . n_{\text {biofuel }}^{-}[\mathrm{MWh} / \mathrm{y}]$ is the production of biofuel replacing a fossil alternative with its corresponding specific emissions $c_{\text {fossil fuel }}$. Only the combustion emissions for the fossil alternative that is replaced are accounted for assuming comparable greenhouse gas emissions for the distribution of the biofuel alternative. As biomass is not considered $\mathrm{CO}_{2}$ neutral but seen as a limited resource its increased use will lead to higher $\mathrm{CO}_{2}$ emissions on a system level as indicated by the first term in the numerator on the right hand side in eq. (5). The specific emissions $c_{b i o}$ allocated to the biomass depend on the reference user of biomass and the alternative fossil fuel used. In order to illustrate the difference for estimated $\mathrm{CO}_{2}$ emission consequences, an additional evaluation is done assuming biomass use to be $\mathrm{CO}_{2}$ neutral for the combustion emissions. This will result in the specific emissions of biomass use $c_{b i o}$ being close to zero, but also may affect the emissions for electricity and district heat production, if biomass-based technologies are used to provide these energy services. 
The published version of the article is available at http://dx.doi.org/10.1016/j.apenergy.2012.03.034. Published in Applied Energy 2013, 101, p. 203-212, DOI: 10.1016/j.apenergy.2012.03.034

\subsection{Economic evaluation}

As it is difficult to estimate the investment costs for a non-mature process such as second generation biofuel production, the economic evaluation in this study is based on the investment opportunity $I O$, representing the specific annual earnings for the production of biofuel according to eq. (6). The investment opportunity $I O$ is then defined as the annualized investment cost for which the plant can achieve break-even operation, i.e. for which annualized investment costs are exactly equal to the net annual earnings. Investment costs can be annualized using the annuity factor, also referred to as the capital recovery factor.

$$
I O=\frac{n_{\text {biofuel }}^{-} \cdot p_{\text {biofuel }}+\left(n_{e l}^{-}-n_{e l}^{+}\right) \cdot p_{e l}+\left(n_{q}^{-}-n_{q}^{+}\right) \cdot p_{q}-n_{b i o}^{+} \cdot p_{b i o}}{n_{\text {biofuel }}^{-}}
$$

In eq. (6) $n_{i}$ represents the annual amount of fuel/service $i$ that is produced (-) or consumed $(+)$ and $p_{i}$ its corresponding costs per energy unit. To get a correct absolute estimate of the investment of the investment opportunity it would be necessary to account for the operation and maintenance $(\mathrm{O} \& \mathrm{M})$ costs as well. However, since the main goal of this study is the comparison of two stand-alone plants (SNG production and CHP plant) with integrated process configurations, the O\&M costs can be expected to be similar for an integrated plant compared to stand-alone plants delivering the same energy services. For a comparative analysis they can therefore be omitted. The difference in investment opportunity between the stand-alone case and the integrated solution $\Delta I O$ therefore represents the increased income and thereby the economic opportunities for realizing the integration between the two processes.

$$
\Delta I O=I O_{\mathrm{SNG}} \text { integrated to } \mathrm{CHP}-I O_{\mathrm{SNG} \& C H P \text { as stand-alone }}
$$

\subsection{Energy market scenarios}

For the definition of the background energy system, four different energy market scenarios for around year 2030 are depicted using the ENPAC tool (version 1.6) [15]. The only user input to the tool are two fossil fuel price (oil, gas and coal) and $\mathrm{CO}_{2}$ emission charge levels. The tool determines - based on underlying investment and running costs - the build-margin technologies for electricity generation as well as the associated emissions. The energy production technology represents the long-term margin and no dynamic effects of the parallel implementation of renewable power production are taken into account in the current version of the scenario tool. A simplified way of representing these effects is the option of defining a support for renewable energy production. This has been done in the current study - setting the support to $20 €_{2005} / \mathrm{MWh}_{\mathrm{el}}$. For the fossil fuel price levels the low and high level estimates according to the World Energy Outlook 2011 of the International Energy Agency [23] are used (low - 450 Scenario, high - Current Policies Scenario). The $\mathrm{CO}_{2}$ emission charge levels of 27 and $85 €_{2005} / \mathrm{t} \mathrm{CO}_{2}$ that have been used are thought to represent low and high ambitions for $\mathrm{CO}_{2}$ emission reduction, respectively. All prices are evaluated in $€_{2005}$ with the 
The published version of the article is available at http://dx.doi.org/10.1016/j.apenergy.2012.03.034. Published in Applied Energy 2013, 101, p. 203-212, DOI: 10.1016/j.apenergy.2012.03.034

corresponding exchange rates applied when necessary as the scenario tool in the present version is using 2005 as base year.

An additional assumption made for the scenario modelling is the choice of technology being the competing user of biomass. In the current study it was set to co-firing in coal power plants. Accounting for the fact that fossil-based power generation technologies are assumed to constitute the build-margin in the scenarios within a European context [15, 22], coal-power plants as the main user of biomass for co-firing are a reasonable choice. The latter assumption implies the important aspect that the use of biomass - considering the combustion emissions is not $\mathrm{CO}_{2}$ neutral, reflecting the underlying assumption that biomass is not an unlimited resource. It is assumed that the reserves of fossil fuels will still outreach by far the potential for sustainable use of biomass for energy use. This implies that the marginal user of biomass for energy purposes will have to replace the share of biomass, that is to be used in a newly implemented biomass-based process, with a fossil alternative. This thereby will lead to indirect emissions for the use of the biomass in the new process. It is of interest to state that the $\mathrm{CO}_{2}$ emissions associated to biomass use are the same for all scenarios, whether coalpower plants are using CCS technology or not. This is consistent as the scenarios are evaluating the changes in $\mathrm{CO}_{2}$ emissions, and these are similar for both biomass-based fuels (change from zero to negative combustion emissions) and fossil fuels (change from positive to zero combustion emissions) when considering CCS technology. The $\mathrm{CO}_{2}$ emissions for the different fuels are evaluated on a life cycle basis including emissions associated with production and distribution [24]. Land use change impacts or the influence of soil carbon dynamics on the greenhouse gas balance of the fuels however are not taken into account in the current version of the tool.

The district heat market is difficult to represent with a general model as it is largely dependent on the plant location and no global or even national market with common reference technologies exists. For this study it is assumed that the excess heat from the SNG plant is competing with combined heat and power (CHP) plants for intermediate heating load. This technology therefore determines the economic value of available excess heat accounting for the complete investment costs for a new CHP plant. This reasoning is a generalisation that overestimates the value of excess heat that needs to be considered in the analysis of the results. The annual full load operation of the CHP plant being the reference producer of district heat is assumed to be 5000 hours. During these hours the SNG plant (assumed full load operation of $8000 \mathrm{~h} / \mathrm{y}$ ) can expect to sell its available excess heat to the corresponding market price. For the integrated solutions this implies that cogeneration of power and heat for the SNG process only is possible during part of the year as well $(5000 \mathrm{~h} / \mathrm{y})$. The rest of the year the integrated plants are operating in the same way as the stand-alone alternative. This actually should be possible due to the flexibility of the integration of the indirect gasification unit $[25,26]$. These assumptions are supposed to reflect a location for the SNG plant close to a larger city such as Gothenburg/Sweden with a well developed district heating network and a number of competing excess heat suppliers. Costs for extra piping necessary to connect the SNG plant to the district heating grid are not accounted for in this study. Table 1 summarises 
The published version of the article is available at http://dx.doi.org/10.1016/j.apenergy.2012.03.034. Published in Applied Energy 2013, 101, p. 203-212, DOI: 10.1016/j.apenergy.2012.03.034

the assumptions and resulting figures for the four energy market scenarios for the year 2030 used in this study.

Table 1. Energy market scenarios for 2030.

\begin{tabular}{|c|c|c|c|c|c|}
\hline \multicolumn{2}{|l|}{ Scenario } & 1 & 2 & 3 & 4 \\
\hline \multicolumn{2}{|l|}{ Fossil fuel price level (input) ${ }^{a}$} & low & low & high & high \\
\hline Crude oil & $€_{2005} / \mathrm{MWh}_{\mathrm{LHV}}$ & 40 & 40 & 55 & 55 \\
\hline Natural gas & $€_{2005} / \mathrm{MWh}_{\mathrm{LHV}}$ & 22 & 22 & 28.5 & 28.5 \\
\hline Coal & $€_{2005} / \mathrm{MWh}_{\mathrm{LHV}}$ & 6.5 & 6.5 & 10 & 10 \\
\hline \multirow[t]{2}{*}{$\mathrm{CO}_{2}$ charge (input) } & & low & high & low & high \\
\hline & $€_{2005} / \mathrm{t} \mathrm{CO}_{2}$ & 27 & 85 & 27 & 85 \\
\hline \multicolumn{6}{|c|}{ End user prices and policy instruments } \\
\hline Wood fuel (forest residue) & $€_{2005} / \mathrm{MWh}_{\mathrm{LHV}}$ & 24 & 44 & 28 & 48 \\
\hline Electricity (incl. $\mathrm{CO}_{2}$ charge) & $€_{2005} / \mathrm{MWh}_{\mathrm{el}}$ & 51 & 67 & 58 & 77 \\
\hline 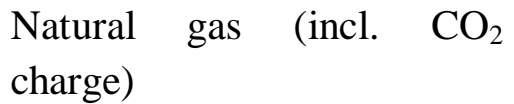 & $€_{2005} / \mathrm{MWh} \mathrm{LHV}_{\mathrm{L}}$ & 32 & 45 & 39 & 51 \\
\hline \multicolumn{2}{|c|}{ Reference electricity production technology ${ }^{b}$} & Coal & Coal,CCS & Coal & Coal,CCS \\
\hline District heating $^{c}$ & $€_{2005} / \mathrm{MWh}_{\mathrm{q}}$ & 51 & 71 & 53 & 72 \\
\hline $\begin{array}{l}\text { Renewable electricity } \\
\text { support (input) }\end{array}$ & $€_{2005} / \mathrm{MWh}_{\mathrm{el}}$ & 20 & 20 & 20 & 20 \\
\hline \multicolumn{6}{|l|}{$\mathrm{CO}_{2}$ emissions } \\
\hline Electricity & $\mathrm{kg} \mathrm{CO} / \mathrm{MWh}_{\mathrm{el}}$ & 679 & 129 & 679 & 129 \\
\hline Biomass $^{e}$ & $\mathrm{~g} \mathrm{CO}_{2} / \mathrm{MWh}_{\mathrm{LHV}}$ & 336 & 336 & 336 & 336 \\
\hline Natural gas & $\mathrm{g} \mathrm{CO}_{2} / \mathrm{MWh}_{\mathrm{LHV}}$ & $202 / 217^{f}$ & $202 / 217^{f}$ & $202 / 217^{f}$ & $202 / 217^{f}$ \\
\hline District heating $^{c}$ & $\mathrm{~kg} \mathrm{CO}_{2} / \mathrm{MWh}_{\mathrm{q}}$ & 156 & 387 & 156 & 387 \\
\hline
\end{tabular}

a) World market prices for 2030 [23] low: oil $97.0 \mathrm{USD}_{2010} / \mathrm{boe}$, gas $9.7 \mathrm{USD}_{2010} / \mathrm{MBtu}_{\mathrm{HHV}}$, coal: 73.7 $\mathrm{USD}_{2010} / \mathrm{t}$; high: oil $134.5 \mathrm{USD}_{2010} /$ boe, gas: $12.6 \mathrm{USD}_{2010} / \mathrm{MBtu}_{\mathrm{HHV}}$, coal: $115.9 \mathrm{USD}_{2010} / \mathrm{t}$; Conversion factors used: Energy: 1 boe $=1.60 \mathrm{MWh}_{\mathrm{LHV}}, 1 \mathrm{MBtu}=0.2931 \mathrm{MWh}, \mathrm{LHV}_{\text {natural gas }} / \mathrm{HHV}_{\text {natural gas }}=0.9, \mathrm{LHV}_{\text {coal }}=23.5$ $\mathrm{MJ} / \mathrm{kg}=6.5 \mathrm{MWh} / \mathrm{t}$; Costs: conversion between years: Harmonized index for consumer prices (HICP) EU27 [27] - index value 2005: 100; index value 2010: gas/liquid fuels/solid fuels - 135.38 / 123.21 / 140.26; Exchange rate $€_{2005} / \mathrm{USD}_{2005}=0.806$

b) $\eta_{e l, \text { Coal }}=0.51, \eta_{e l, \text { Coal, } C C S}=0.40$

c) biomass CHP plant $\eta_{\text {tot }}=1.08, \alpha=0.42$ [28]

d) average value for Europe [15]

e) Coal power plant reference user of biomass

f) combustion only / life cycle perspective (incl.production and transport) [24]

\section{SNG production process}

The biofuel production process chosen for illustrating the application of the described methodology is a production process for SNG from biomass. The process has been designed as an extension of an existing combined heat and power (CHP) plant [25] using an indirect gasification technology [26]. Two alternative drying technologies for the SNG biomass fuel and two levels of heat integration between the SNG and CHP process, resulting in four different configurations, are evaluated. The general concept for the process integration is illustrated in Figure 2. 
The thermal load of both the combustion boiler and the gasification unit is set to $100 \mathrm{MW}_{\text {th }}$. For the CHP steam power plant, no feedstock drying is assumed with the fuel being fed at 50 wt-\% moisture according to the reference data the model is based on [28]. The biomass fuel fed to the SNG process is dried from its initial moisture content of 50 to $20 \mathrm{wt}-\%$ prior to gasification. The thermal input on a wet fuel basis to the SNG process is therefore less than $100 \mathrm{MW}_{\text {th }}$ on a lower heating value (LHV) basis due to the higher moisture content. The biomass fuel input to the CHP plant decreases for the integrated solutions as additional fuel is supplied to the boiler in the form of non-gasified char. At the same time the steam generation decreases in the CHP plant since part of the boiler duty is used for running the endothermic gasification process. This decrease in steam generation can be partially compensated for by thermally integrating the two processes making use of excess heat from the SNG process for increasing the steam generation within the CHP plant.

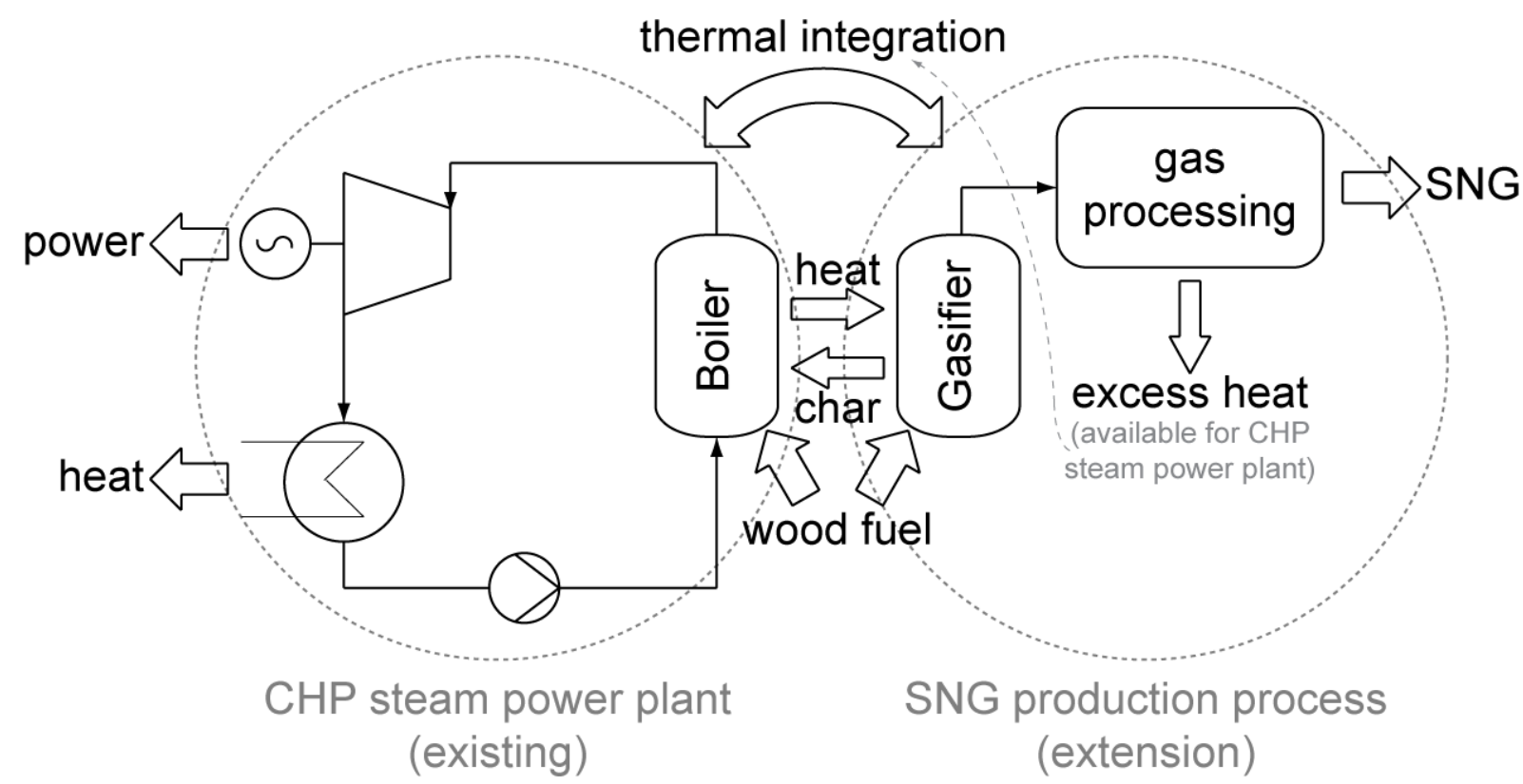

Figure 2: Concept of integrating SNG production to existing energy infrastructure in form of CHP steam power plants [28].

The two alternative feedstock drying technologies prior to the gasification step that are evaluated within the process design are steam drying (case 1) and low-temperature air drying (case 2). The two levels of thermal integration represented are a balancing (case A) and a maximum integration (case B) case. In the case of balancing thermal integration (A) only the freely available excess heat from the SNG process is used for steam generation and consecutive power and district heat generation within the CHP steam power plant. Maximum thermal integration cases (B) refer to a tight thermal integration between the SNG and CHP plant, even making use of internal heat pockets within the SNG process in order to maximise the overall electricity generation. In this case, all high temperature heat available from the SNG process is used to generate steam that is supplied to the CHP plant. After expansion in the steam turbine, low pressure steam is returned to the SNG plant where it is used to provide low temperature process heating that is supplied by high temperature excess process heat in 
Case A process configurations. For further details on the integration study, the reader is referred to [25].

In order to evaluate the integrated solutions in comparison to a stand-alone SNG plant an additional case has been defined in this study for an SNG plant of similar design where only the non-gasified char is used in the combustion unit, supplying heat to the gasification process. The remaining energy in the flue gases is used for combustion air preheating and district heating purposes. No power generation is assumed for the stand-alone case, the process' energy performance thereby resembling the first industrial scale SNG plant that is currently under construction in Gothenburg/Sweden [29]. The existing CHP steam power plant is operating in the same way as before without any modifications for the stand-alone case. In Figure 3 the two alternatives for introduction of SNG production (stand-alone (1 case) and integrated solutions (4 cases)) are illustrated, also indicating the yearly operating hours as discussed in the energy market scenario section. Table 2 summarizes the key energy figures for the SNG stand-alone plant, for the four integration cases, as well as for the CHP plant with which the SNG process is integrated.

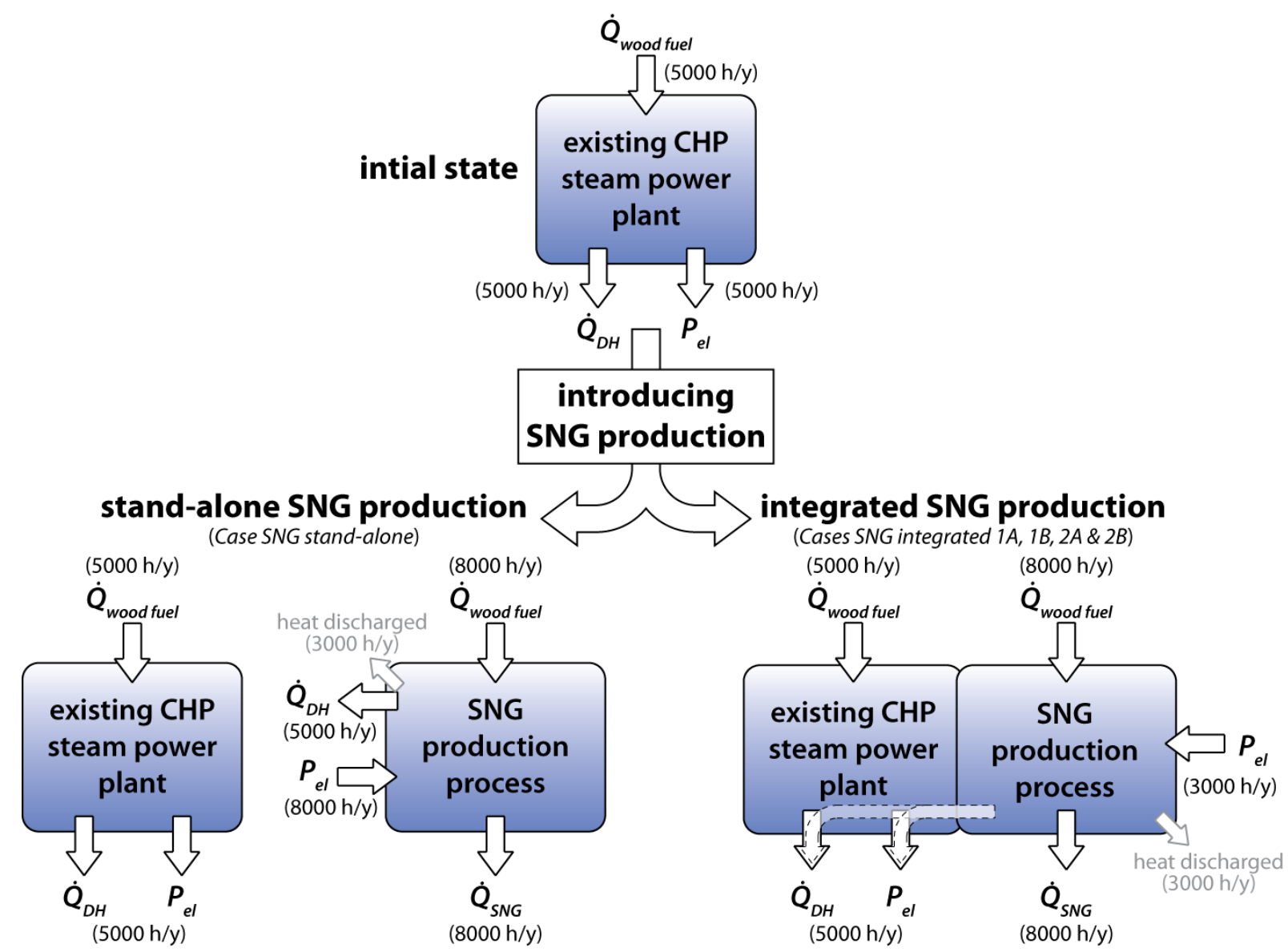

Figure 3. Illustration of the stand-alone and integrated operation for the SNG production process as extension of an existing CHP steam power plant. 
The published version of the article is available at http://dx.doi.org/10.1016/j.apenergy.2012.03.034. Published in Applied Energy 2013, 101, p. 203-212, DOI: 10.1016/j.apenergy.2012.03.034

Table 2. Key energy figures for SNG production alternatives and CHP stand-alone plant (based on [25]).

\begin{tabular}{|c|c|c|c|c|}
\hline & $\begin{array}{c}\text { Wood fuel } \\
\text { input } \\
\dot{Q}_{\text {fuel }}\end{array}$ & $\begin{array}{c}\text { SNG production } \\
\dot{Q}_{S N G}\end{array}$ & $\begin{array}{c}\text { Net electricity } \\
\text { production } \\
P_{e l}\end{array}$ & $\begin{array}{c}\text { District heat } \\
\text { production } \\
\dot{Q}_{D H}\end{array}$ \\
\hline & $\mathrm{MW}_{\mathrm{LHV}}{ }^{1)}$ & $\mathrm{MW}_{\mathrm{LHV}}$ & MW & MW \\
\hline SNG stand-alone ${ }^{2)}$ & 90,3 & 62,7 & $-3,4$ & 20,3 \\
\hline CHP stand-alone & 100 & - & 31,7 & 76,8 \\
\hline SNG integrated $1 A^{2) 3)}$ & 161,9 & 62,7 & 24,7 & 68,4 \\
\hline SNG integrated $1 B^{2) 4)}$ & 161,9 & 62,7 & 27,6 & 64,1 \\
\hline SNG integrated $2 A^{5) 3)}$ & 161,9 & 62,7 & 23,2 & 60,1 \\
\hline SNG integrated $2 B^{5) 4)}$ & 161,9 & 62,7 & 28,3 & 54,9 \\
\hline
\end{tabular}

\section{Results and Discussion}

All results are reported on a per year basis. Table 3 gives the energy figures for the four integrated cases of SNG production and the stand-alone solution. In addition the absolute change with respect to the initial conditions (only the existing CHP plant operating) is indicated.

For the thermodynamic performance evaluation with the system efficiency $\eta_{\text {sys }}$ according to eq. (4) it has to be accounted for the fact that the reference heat production technology is a cogeneration technology. In addition, since excess heat from the SNG plant can only be delivered to the district heating network during part of the year, it is necessary to evaluate the efficiency based on the energy performance per year basis instead of the nominal duties. The system efficiency for this specific case is thus defined as:

$$
\eta_{s y s}=\frac{n_{S N G} \cdot L H V_{S N G}+\frac{\left(P_{e l}^{-}-\alpha_{r e f} \cdot Q^{-}\right)}{\eta_{e l, r e f}}+\frac{Q^{-}}{\eta_{q, r e f}}}{n_{\text {wood fuel }} \cdot L H V_{\text {woodfuel }}+\frac{\left(\alpha_{r e f} \cdot Q^{-}-P_{e l}^{-}\right)}{\eta_{e l, r e f}}+\frac{Q^{+}}{\eta_{q, \text { ref }}}}
$$

In eq. (8) $n_{i} \cdot L H V_{i}$ represents the energy input and output of fuel $i$. $\alpha_{r e f}$ is the power-to-heat ratio of the reference cogeneration heat production technology. Exported heat from the process causes a decrease in electricity production on the system level of $\alpha_{r e f} \cdot Q^{-}$as the reference cogeneration plant operation will be decreased. The difference between the net electricity export $P_{e l}^{-}$and the term $\alpha_{\text {ref }} \cdot Q^{-}$determines whether a net increase or reduction of primary energy use for electricity is induced by the process on a system level. Again, only positive terms are counted in eq. (8). 
The published version of the article is available at http://dx.doi.org/10.1016/j.apenergy.2012.03.034. Published in Applied Energy 2013, 101, p. 203-212, DOI: 10.1016/j.apenergy.2012.03.034

Table 3. Annual energy figures for the different process alternatives.

\begin{tabular}{|c|c|c|c|c|c|c|c|c|}
\hline & \multicolumn{2}{|c|}{ Wood fuel } & \multicolumn{2}{|c|}{$S N G$} & \multicolumn{2}{|c|}{ Electricity } & \multicolumn{2}{|c|}{ District heat } \\
\hline & GWh/y & $\Delta^{1)}$ & GWh/y & $\Delta^{1)}$ & GWh/y & $\Delta^{1)}$ & GWh/y & $\Delta^{1)}$ \\
\hline SNG stand-alone $e^{2)}$ & 1222 & 722 & 502 & 502 & 132 & -27 & 485 & 101 \\
\hline SNG integr. $1 A^{2 / 3)}$ & 1080 & 580 & 502 & 502 & 113 & -45 & 342 & -42 \\
\hline SNG integr. $1 B^{2 / 3)}$ & 1080 & 580 & 502 & 502 & 128 & -31 & 321 & -64 \\
\hline SNG integr. $2 A^{244)}$ & 1080 & 580 & 502 & 502 & 104 & -55 & 301 & -84 \\
\hline SNG integr. $2 B^{244)}$ & 1080 & 580 & 502 & 502 & 131 & -27 & 275 & -110 \\
\hline
\end{tabular}

${ }^{\mathrm{T}}$ change in annual production/consumption compared to inital state with existing CHP plant only $\left(Q_{\text {wood fuel }}=500 \mathrm{GWh} / \mathrm{y}\right.$,

$\left.P_{e l}=159 \mathrm{GWh} / \mathrm{y}, Q_{D H}=384 \mathrm{GWh} / \mathrm{y}\right)$

2) the absolute energy figure numbers are for both the CHP and SNG plant

${ }^{3)}$ electricity consumption of 3.4 MW during SNG-only mode (3000 h/y)

4) electricity consumption of $4 \mathrm{MW}$ during SNG-only mode $(3000 \mathrm{~h} / \mathrm{y})$

In Figure 4 the system energy efficiency $\eta_{s y s}$ is illustrated for the different process alternatives and the four energy market scenarios. The difference in efficiency for this specific case study can be mainly attributed to the varying electrical efficiency of the reference production technology in the corresponding scenario. A lower reference electrical efficiency in scenarios 2 and 4 (coal condensing power plant with CCS) implies a better performance of the integrated solutions compared to the stand-alone alternative. An increased thermal integration (comparing cases B to A) leads to better system efficiency for all scenarios. For scenarios 1 and 3 integrated solutions perform worse than the stand-alone alternative except for the integrated SNG production with steam drying at maximum thermal integration (case 1B). The latter case is the one performing best within all scenarios. It has to be stated though that the range of variation for $\eta_{s y s}$ between the cases within one scenario is less than $3 \%$-points for all scenarios.

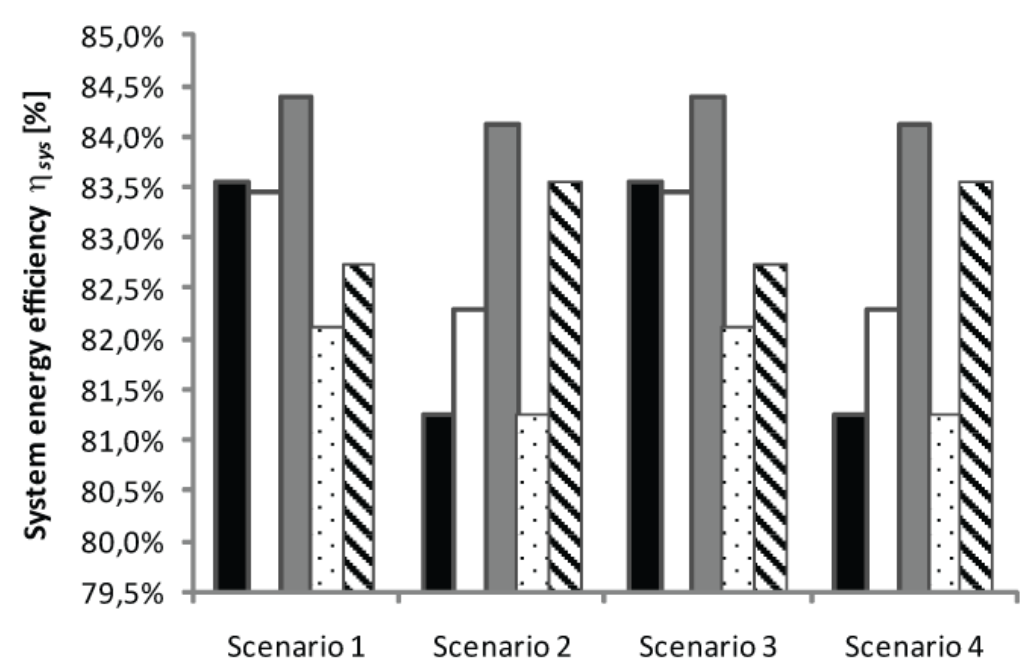

Figure 4. System energy efficiency $\eta_{s y s}$ for the different SNG production cases in the four energy market scenarios. Black: stand-alone, white: integrated 1A, grey: integrated 1B, dotted: integrated 2A, dashed: integrated 2B. 
When analysing the $\mathrm{CO}_{2}$ emission consequences of the introduction of an SNG production process it can be stated that all alternatives lead to an increase in $\mathrm{CO}_{2}$ emissions per year for the given scenarios. For scenarios 1 and 3 where the reference electricity production technology is coal-based condensing power without CCS the integrated solutions result in a better performance, while for scenarios 2 and 4, a stand-alone plant is the better option. This is due to the substantially higher amount of external electricity production for the stand-alone solution that leads to lower $\mathrm{CO}_{2}$ emissions when this electricity is produced with $\mathrm{CCS}$ technology. The associated $\mathrm{CO}_{2}$ emissions for biomass use do not differ between the scenarios and therefore are not the reason for the different results between the scenarios. With the reference user of biomass being a coal condensing power plant, the associated emissions of biomass use are approximated with emissions from coal combustion, CCS being used or not. This is an approximation that is valid as in case of CCS the negative $\mathrm{CO}_{2}$ emission effect of biomass $\left(\mathrm{CO}_{2}\right.$ released during biomass combustion is stored underground resulting in a negative $\mathrm{CO}_{2}$ emission from a life cycle perspective) is lost when it is replaced by fossil coal.

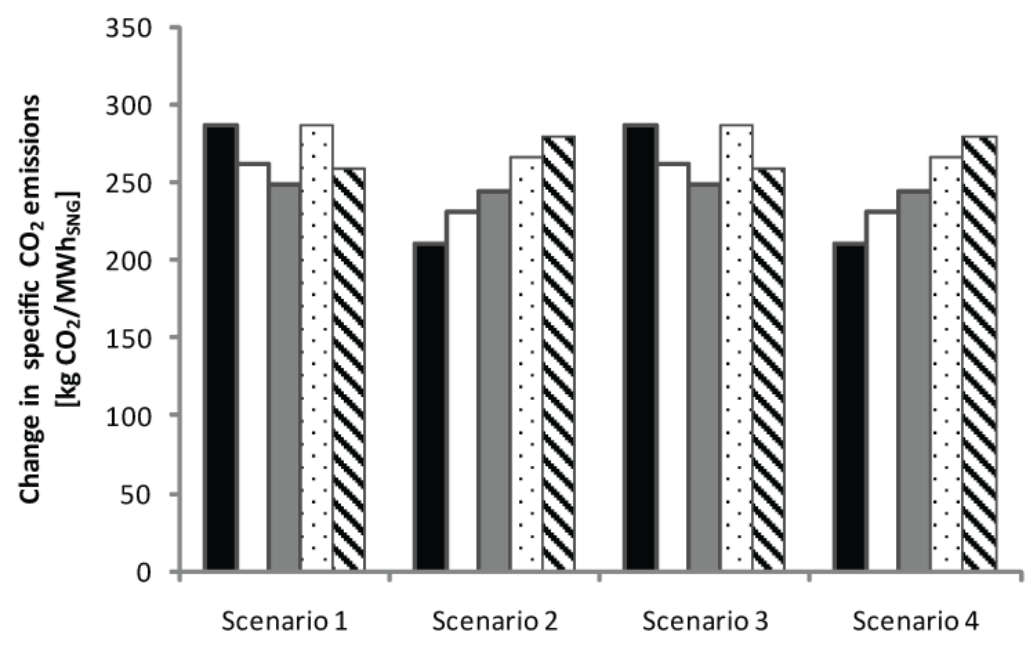

Figure 5. $\mathrm{CO}_{2}$ consequences for the different $\mathrm{SNG}$ production processes in the four energy market scenarios. Black: stand-alone, white: integrated 1A, grey: integrated 1B, dotted: integrated 2A, dashed: integrated 2B.

The fact that all cases lead to an increase in $\mathrm{CO}_{2}$ emissions can be explained by the fact that biomass combustion is not considered $\mathrm{CO}_{2}$ neutral in this study and that for all cases the reference user of biomass is a coal power plant. This puts a large emission penalty on biomass to start with. In addition the SNG produced from biomass replaces fossil natural gas having lower specific emissions than coal. The $\mathrm{CO}_{2}$ balance for the SNG process can therefore hardly be positive with the given assumptions.

Economically, all SNG production alternatives are not feasible as such within any of the scenarios. The annual investment opportunity for the different cases given in Figure 6 shows very low values of several thousand $€$ per $\mathrm{GWh}_{\mathrm{SNG}}$, making it impossible to finance such a project. The difference in investment opportunity $\Delta I O$ between integrated and stand-alone cases is negative for all cases and scenarios, rendering an integration of the two processes economically unattractive. These figures clearly demonstrate that the economic viability of SNG 
production (and biofuels in general) is largely dependent on the existence of specific support policies. No biofuel support policy has been assumed in the current study. The necessity of such a policy for rendering biofuel process alternatives economically interesting has been also been stated by Wetterlund and Söderström [30], among others. An additional factor influencing the investment opportunity of the integrated solutions negatively is the fact that the district heat delivery is decreasing. The decreased district heat production having to be compensated by external combined heat and power plants (e.g. a new CHP plant has to be built to cover the decreased heat delivery) puts high economical burdens on the integrated solutions. Such solutions therefore only would be viable in case of a decreasing heat demand on the end-user side or cheaper alternatives than building a new CHP plant for covering the deficit in DH production.

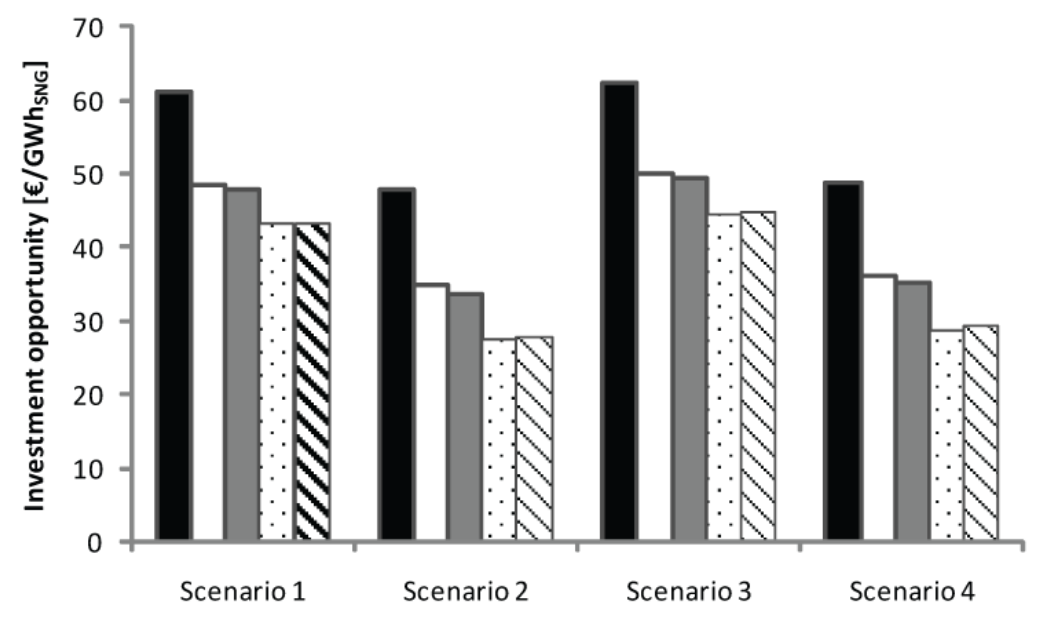

Figure 6. Specific investment opportunity $I O$ for the different SNG production processes in the four energy market scenarios. Black: stand-alone, white: integrated 1A, grey: integrated 1B, dotted: integrated 2A, dashed: integrated 2B.

To illustrate possible performance improvements for the SNG production process from a system level perspective, an additional investigation on the opportunities for carbon storage from the SNG process has been performed. CCS for the biomass-based process can be analysed in the same way as fossil $\mathrm{CO}_{2}$ storage with the applied scenario methodology. The $\mathrm{CO}_{2}$ emissions allocated to the biomass use will not change whether the marginal biomass user in the background energy system is a coal power plant with or without CCS as only changes in $\mathrm{CO}_{2}$ emissions are analysed. This is illustrated by the emission factor for biomass $(336 \mathrm{~kg}$ $\mathrm{CO}_{2} / \mathrm{MWH}_{\mathrm{LHV}}$ for all scenarios) in Table 1 and has already been discussed in Sections 2.3 and 2.5. The methodology therefore is consistent for CCS both on biomass and fossil fuel processes. During SNG production storage-ready $\mathrm{CO}_{2}$ is separated that is vented to the atmosphere in the study the current results are based on [25]. The $\mathrm{CO}_{2}$ is at high level of purity in two streams within the SNG process, one of them also containing traces of $\mathrm{H}_{2} \mathrm{~S}$, making further treatment before compression and storage necessary. Both streams are assumed to be sent to storage in a simplified estimation of the $\mathrm{CO}_{2}$ consequences and investment opportunity $I O$. It should be stated that CCS on biomass-based processes currently is not a viable option as biomass based $\mathrm{CO}_{2}$ emissions are not included in the European emission trading system. It might become viable 
once included, but in fact a recent research study investigating the potential for CCS within the pulp and paper industry points out that CCS on biomass-based applications needs a very heavy investment on the $\mathrm{CO}_{2}$ storage infrastructure as most of the plants are situated rather remotely [31]. Assuming CCS to be implemented in the future, the infrastructure will rather be located in the vicinity of the large $\mathrm{CO}_{2}$ emission source cluster - mainly consisting of fossil fuel power plants and refineries in Central Europe [31].

Only the amount of $\mathrm{CO}_{2}$ stored is accounted for in this simplified analysis, neglecting marginal effects of increased electricity consumption within the SNG process for the compression of $\mathrm{CO}_{2}$. The amount of $\mathrm{CO}_{2}$ stored per year for all SNG production cases amounts to about 101300 t. Figure 7 shows the resulting $\mathrm{CO}_{2}$ emission consequences and investment opportunity results .
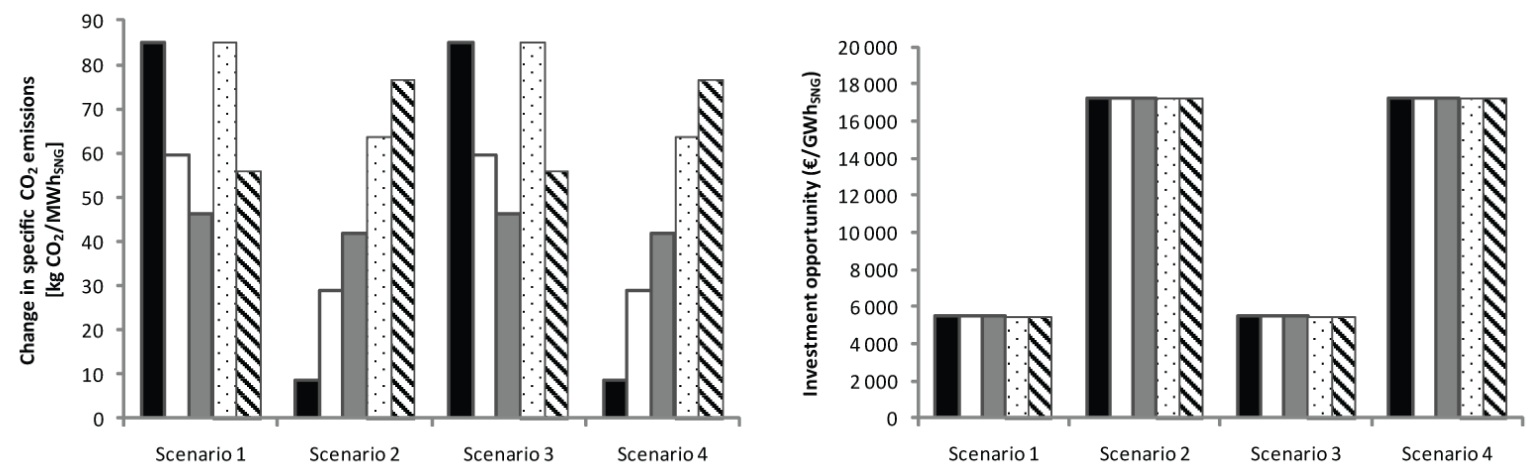

Figure 7. $\mathrm{CO}_{2}$ consequences and investment opportunity for the different SNG production processes considering capture and storage of the $\mathrm{CO}_{2}$ separated in the SNG process. Black: stand-alone, white: integrated 1A, grey: integrated 1B, dotted: integrated $2 \mathrm{~A}$, dashed: integrated $2 \mathrm{~B}$.

Considering the influence of $\mathrm{CO}_{2}$ storage on the investment opportunity it can be stated that a substantial increase can be observed. This increase has to be weighed against the increased investment costs for the plant when implementing $\mathrm{CO}_{2}$ storage. Another interesting observation is the fact that the difference between the stand-alone and integrated alternatives becomes negligible. The influence of $\mathrm{CO}_{2}$ storage becomes very dominant for the economic viability, in particular for the scenarios with high $\mathrm{CO}_{2}$ emission charges (scenario 2 and 4). The change in $\mathrm{CO}_{2}$ emissions is still positive but the numbers are substantially reduced compared to no $\mathrm{CO}_{2}$ storage (Figure 5). Allocating in addition lower specific emissions to biomass would improve the performance additionally. For the purpose of illustration the specific change in $\mathrm{CO}_{2}$ emissions is shown for the case where the specific combustion emissions of biomass $c_{b i o}$ are zero in Figure 8. This implies that the biomass use is $\mathrm{CO}_{2}$ neutral except for the greenhouse gas emissions related to harvest and fuel transport. It also results in negative specific emissions for the district heat $c_{q}$ as this technology is biomassbased as well and the cogenerated electricity replaces fossil-based electricity. $\mathrm{No}^{\mathrm{CO}_{2}}$ storage is taken into account for the figures represented in Figure 8 but still the change in specific emissions is negative. Adding $\mathrm{CO}_{2}$ storage would further improve the results. This evaluation could be considered relevant when the marginal electricity production is assumed to be a 
The published version of the article is available at http://dx.doi.org/10.1016/j.apenergy.2012.03.034. Published in Applied Energy 2013, 101, p. 203-212, DOI: 10.1016/j.apenergy.2012.03.034

renewable technology such as hydro or solar power or even biomass-based power generation. The emissions related to biomass use (e.g. combustion) can then be considered negligible assuming a sustainable management, and the greenhouse gas emissions comparison between different process alternative for biomass use then boils down to the LCA based emissions. In that case it would be important to not only take into account emissions due to fuel transport and harvest, but also account for indirect effects cause by land use change and carbon soil dynamics. Cherubini et al. [8] indicated that these land use change effects can have a considerable influence on the greenhouse gas balance of biorefinery systems from crop residues. The fuel in mind for the proposed SNG process though will be forest residues where the land use change effects are considerably lower [32,33]. The greenhouse gas balance of harvesting forest residues accounting for soil carbon is shown to be heavily dependent among other factors such as site productivity, geographical location - on the time-scale the evaluations are based on. In a long-term perspective little effect on soil carbon is to be expected from forest residues [33].

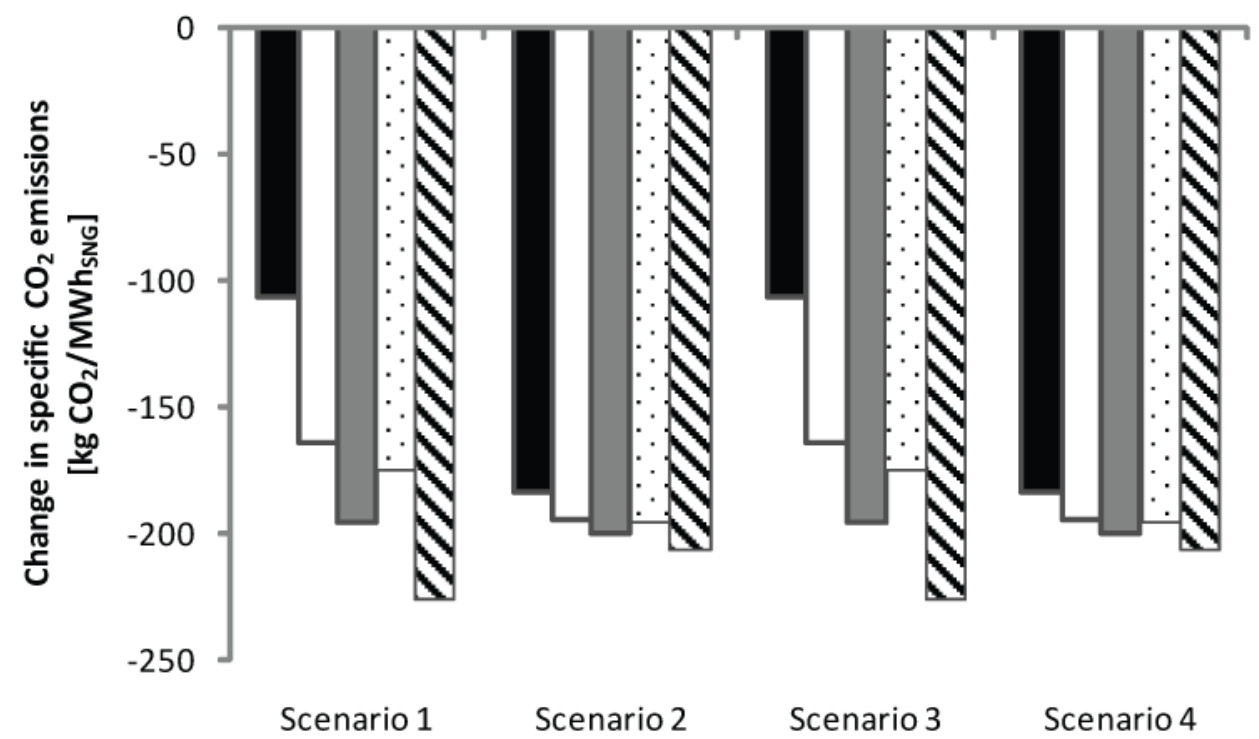

Figure 8. $\mathrm{CO}_{2}$ consequences for the different $\mathrm{SNG}$ production processes considering biomass use $\mathrm{CO}_{2}$ neutral. Black: stand-alone, white: integrated $1 \mathrm{~A}$, grey: integrated $1 \mathrm{~B}$, dotted: integrated 2A, dashed: integrated 2B.

\section{Conclusions}

In this paper, a systematic way of evaluating the performance of biofuel production processes using energy market scenarios has been demonstrated. Using this approach, a multi-faceted evaluation is possible accounting for the energy and economic performance, as well as for the $\mathrm{CO}_{2}$ consequences within different possible future energy background. The three performance indicators thereby can be used as supporting tool for policy-makers. The method has been demonstrated for the example of SNG production process alternatives designed as stand-alone plant, or as integrated solutions to an existing CHP steam power plant. The energy performance on a system level of the integrated solutions is superior to the stand-alone alternative for all scenarios when aiming at a high level of thermal integration. The economic 
evaluation shows little to no profitable opportunities for SNG production from biomass in all scenarios. Additional policy support would be needed to render SNG production economically viable. The $\mathrm{CO}_{2}$ emissions for $\mathrm{SNG}$ production increase for all scenarios due to the underlying assumption of biomass combustion not being $\mathrm{CO}_{2}$ neutral and coal power plants being the reference user of biomass. Adopting the more conventional approach of considering $\mathrm{CO}_{2}$ emissions during biomass combustion to be negligible, the results are changed considerably showing a reduction of $\mathrm{CO}_{2}$ emissions by introducing SNG production for replacing natural gas. Nevertheless, there remains a certain degree of uncertainty considering the indirect greenhouse gas effects of biomass such as harvesting, transport and emissions due to land use change. This way of interpreting the results furthermore neglects the fact that biomass will be a resource with a rather limited potential in comparison to fossil alternatives such as coal or gas in the medium to long term, resulting in an overestimation of the GHG emission reduction potential of the process. Based on the figures showing increased $\mathrm{CO}_{2}$ emissions by introducing SNG production, the concept of replacing fossil natural gas by SNG produced from biomass seems questionable at first sight. The use of SNG though has not been specified in this study. When for example thinking specifically of the transport sector, assuming coal power plants as reference users of biomass might not be the best reference background and the $\mathrm{CO}_{2}$ consequence picture will change. Based on the assumptions adopted in this study, it can however be stated that using SNG from biomass for power generation purposes is not beneficial from a $\mathrm{CO}_{2}$ emission perspective. A simplified evaluation of the influence of $\mathrm{CO}_{2}$ storage within the SNG production process on the $\mathrm{CO}_{2}$ emission consequences on the system level and the investment opportunity shows that $\mathrm{CO}_{2}$ storage is largely dominant over process integration differences between the SNG production alternatives when looking at the investment opportunity. The $\mathrm{CO}_{2}$ emissions are heavily reduced by $\mathrm{CO}_{2}$ storage, but are still increasing for all scenarios when introducing SNG production from biomass. Again, it has to be pointed out that the underlying assumption of biomass being used in coal power plants on a marginal level puts severe emission penalties on the use of biomass as fuel input to the process.

\section{Acknowledgements}

This research project was financially supported by the Swedish Energy Agency and Göteborg Energi's Research Foundation. Support from Erik Axelsson at Profu AB concerning the ENPAC tool is gratefully acknowledged.

\section{Glossary}

$\begin{array}{llll}\text { CCS } & \text { carbon capture and storage } & p & \text { energy-specific costs } \\ \text { CHP } & \text { combined heat and power } & P & \text { power } \\ \text { GHG } & \text { greenhouse gases } & Q / \dot{Q} & \text { heat energy/thermal duty } \\ \text { LCA } & \text { life cycle analysis } & & \\ \text { LHV } & \text { lower heating value } & \text { Indices/Exponents } \\ \text { SNG } & \text { synthetic natural gas } & - & \text { exported } \\ \text { NG } & \text { natural gas } & + & \text { imported }\end{array}$


The published version of the article is available at http://dx.doi.org/10.1016/j.apenergy.2012.03.034. Published in Applied Energy 2013, 101, p. 203-212, DOI: 10.1016/j.apenergy.2012.03.034

$\begin{array}{llll}\text { O\&M } & \text { operation and maintenance } & \text { bio } & \text { biomass } \\ \text { IO } & \text { annual investment opportunity } & \begin{array}{l}\text { el } \\ \text { ex ectrical }\end{array} & \text { exergetic } \\ \text { Symbols } & & \text { fuel } & \text { fuel } \\ \alpha & \text { power-to-heat ratio } & \text { marg } & \text { marginal } \\ c & \text { energy-specific } \mathrm{CO}_{2} \text { emissions } & \text { prod } & \text { product } \\ E & \text { exergy } & q & \text { heat } \\ \eta & \text { efficiency } & \text { ref } & \text { reference } \\ n & \text { annual energy use/production } & \text { sys } & \text { system } \\ & & \text { th } & \text { thermal }\end{array}$

\section{References}

[1] Demirbas A. Political, economic and environmental impacts of biofuels: A review. Appl Energ 2009;86:S108-S17.

[2] EU. Directive on the promotion of the use of energy from renewable sources. Strasbourg: European Commission. <europa.eu/legislation_summaries/energy/renewable_energy/en0009_en.htm>; 2009 . [accessed 14.06.11].

[3] Demirbas MF. Biorefineries for biofuel upgrading: A critical review. Appl Energ 2009;86:S151-S61.

[4] Ajanovic A. Biofuels versus food production: Does biofuels production increase food prices? Energy 2011;36:2070-6.

[5] Timilsina GR, Shrestha A. How much hope should we have for biofuels? Energy 2011;36:2055-69.

[6] Gnansounou E. Assessing the sustainability of biofuels: A logic-based model. Energy 2011;36:2089-96.

[7] Silva Lora EE, Escobar Palacio JC, Rocha MH, Grillo Renó ML, Venturini OJ, Almazán del Olmo O. Issues to consider, existing tools and constraints in biofuels sustainability assessments. Energy 2011;36:2097-110.

[8] Cherubini F, Ulgiati S. Crop residues as raw materials for biorefinery systems - A LCA case study. Appl Energ 2010;87:47-57.

[9] Edwards R, Larivé J-F, Mahieu V, Rouveirolles P. Well-to-wheels Analysis of Future Automotive Fuels and Powertrains in the European Contex, Version 2.c. JEC - Joint Research Centre-EUCAR-CONCAWE collaboration. Ispra, Italy. <iet.jrc.ec.europa.eu/aboutjec/downloads>; 2007. [accessed 14.06.11].

[10] Wetterlund E, Pettersson K, Magnusson M. Implications of system expansion for the assessment of well-to-wheel $\mathrm{CO} 2$ emissions from biomass-based transportation. Int J Energ Res 2010;34:1136-54.

[11] Kalt G, Kranzl L. Assessing the economic efficiency of bioenergy technologies in climate mitigation and fossil fuel replacement in Austria using a techno-economic approach. Appl Energ 2011;88:3665-84. 
The published version of the article is available at http://dx.doi.org/10.1016/j.apenergy.2012.03.034. Published in Applied Energy 2013, 101, p. 203-212, DOI: 10.1016/j.apenergy.2012.03.034

[12] Daianova L, Dotzauer E, Thorin E, Yan J. Evaluation of a regional bioenergy system with local production of biofuel for transportation, integrated with a CHP plant. Appl Energ 2012;92:739-49.

[13] Rubio Rodríguez MA, Ruyck JD, Díaz PR, Verma VK, Bram S. An LCA based indicator for evaluation of alternative energy routes. Appl Energ 2011;88:630-5.

[14] Bram S, De Ruyck J, Lavric D. Using biomass: A system perturbation analysis. Appl Energ 2009;86:194-201.

[15] Harvey S, Axelsson E. Scenarios for assessing profitability and carbon balances of energy investments in industry. AGS Pathways report 2010:EU1. Gothenburg, Sweden: Chalmers University of Technology. 2010.

[16] Pathways to Sustainable European Energy Systems. AGS - Alliance for Global Sustainability. <www.energy-pathways.org/index.htm>; 2011. [accessed 14.06.11].

[17] Szargut J, Morris DR, Steward FR. Exergy analysis of thermal, chemical, and metallurgical processes. New York: Hemisphere; 1988.

[18] Gassner M. Process Design Methodolgy for Thermochemical Production of Fuels from Biomass. Application to the Production of Synthetic Natural gas from Lignocellulosic Resources. Doctoral Thesis. Lausanne, Switzerland: Ecole Polytechnique Fédérale de Lausanne; 2010.

[19] Korobitsyn MA, Jellema P, Hirs GG. Possibilities for gas turbine and waste incinerator integration. Energy 1999;24:783-93.

[20] Petrov MP. Biomass and natural gas hybrid combined cycles. Licentiate Thesis. Stockholm, Sweden: Royal Institute of Technology; 2003.

[21] Pihl E, Heyne S, Thunman H, Johnsson F. Highly efficient electricity generation from biomass by integration and hybridization with combined cycle gas turbine (CCGT) plants for natural gas. Energy 2010;35:4042-52.

[22] Sköldberg H, Unger T. Effects of changes in electricity use/production - model calculations. Report nr. 08:30 (in Swedish). Stockholm, Sweden: Elforsk; 2008.

[23] World Energy Outlook 2011. Paris Cedex, France: International Energy Agency; 2011.

[24] Uppenberg S, Almemark M, Brandel M, Lindfors L-G, Marcus H-O, Stripple H, et al. Facts book for fuels. Report B 1334A-2 (in Swedish). Stockholm, Sweden: IVL; 2001.

[25] Heyne S, Thunman H, Harvey S. Extending existing combined heat and power plants for synthetic natural gas production. Int J Energ Res 2011. doi: 10.1002/er.1828.

[26] Thunman H, Åmand L-E, Leckner B, Johnsson F. A cost effective concept for generation of heat, electricity and transport fuel from biomass in fluidised bed boilers - using existing energy infrastructure. 15th European Biomass Conference \& Exhibition. Berlin, Germany, 2007. p. 1075 - 80.

[27] Harmonized Indices of Consumer Prices (HICP). Eurostat: European Commission. < epp.eurostat.ec.europa.eu/portal/page/portal/hicp/introduction>; 2011. [accessed 20.02.12].

[28] Steinwall P, Johansson K, Svensson S-Å, Adolfsson H, Ekelund N. Optimal steam data for biomass fired CHP plants. Report 777 (in Swedish). Stockholm, Sweden: Värmeforsk; 2002.

[29] Gunnarsson I. The GoBiGas Project. International Seminar on Gasification 2011 - Gas Quality, CHP and New Concepts. Malmö, Sweden: Swedish Gas Center; 2011. 
The published version of the article is available at http://dx.doi.org/10.1016/j.apenergy.2012.03.034. Published in Applied Energy 2013, 101, p. 203-212, DOI: 10.1016/j.apenergy.2012.03.034

[30] Wetterlund E, Söderström M. Biomass gasification in district heating systems - the effect of economic energy policies. Appl Energ. 2010;87:2914-22.

[31] Jönsson J, Berntsson T. Analysing the Potential for CCS within the European Pulp and Paper Industry. 23rd International Conference of Efficiency, Cost, Optimization, Simulation and Environmental Impact of Energy Systems (ECOS 2010). Lausanne, Switzerland, 2010. p. 676-83.

[32] Lindholm EL. Energy use and environmental impact of roundwood and forest fuel production in Sweden. Doctoral Thesis. Uppsala, Sweden: Swedisch University of Agricultural Sciences; 2010.

[33] Lindholm EL, Stendahl J, Berg S, Hansson PA. Greenhouse gas balance of harvesting stumps and logging residues for energy in Sweden. Scandinavian Journal of Forest Research. 2011;26:586-94. 